\title{
IMAGERY-DERIVED BATHYMETRY IN STRAIT OF JOHOR'S TURBID WATERS USING MULTISPECTRAL IMAGES
}

\author{
Kelvin Kang Wee Tang and Mohd Razali Mahmud \\ GeoCoastal Research Unit, Geospatial Imaging and Information Research Group (GI2RG), \\ Universiti Teknologi Malaysia (UTM), 81310 Johor Bahru, Malaysia \\ Email: tkwkelvin2@live.utm.my and razalimahmud@utm.my
}

KEY WORDS: Imagery-Derived Bathymetry, Multispectral Images, Satellite Bathymetry

\begin{abstract}
:
Although vessel-based acoustic sounding technique is accurate, however it is typically constrained by high operating costs, logistic difficulties and limited spatial coverage. It seems it is necessary to employ an alternative approach that can reduce the aforementioned high operation cost. The development of the imagery-derived bathymetry has brought in the new revolution in hydrography. The paper highlights the application of incorporating satellite remote sensing techniques to extract bathymetry information from the freely downloadable Landsat-8 satellite images. In this study, two different band ratio transform empirical models have been utilised to transform the reflected radiances of green and blue bands into bathymetry depths at the coastal region adjacent to Tanjung Kupang, Strait of Johor, Malaysia. The inland swampy area is vegetated by lavish mangroves while the shoreface is fronted by flat slopes with turbid suspended sediment. In the course of experiment, the results from Stumpf et al.'s model and Dierssen et al.'s model show a reasonable agreement, with similar correlation coefficient (r) of 0.76 between the imageryderived depths and in-situ bathymetry depths from vessel-based sounding. The Stumpf et al.'s model has achieved root mean square error (RMSE) of 0.885 metres and mean absolute error (MAE) of 0.631 metres; while Dierssen et al.'s model delivers RMSE of 0.878 metres and MAE of 0.629 metres respectively. Although these two algorithms are slightly different, however the end results produced are quite close in this study. The results show that both empirical models represent a promising outcome and can be used to complement data from vessel-based single beam sounding, which is normally obtained at medium to course profiling resolution for the purpose of survey reconnaissance and survey planning.
\end{abstract}

\section{INTRODUCTION}

Since the past decade, the preface of the remote sensing and geographical information system (GIS) technology has brought in the new revolution to hydrography. Today, human ingenuity has allowed us to perform a vast variety of tasks including bathymetric estimation from multispectral images. The ability of the electromagnetic spectrum (EMR) to penetrate water columns allows us to dig out more useful information via remote sensing technology. Presently, the volume of remotely sensed imagery is now exploding with hundreds of small satellites in space. The commercially available multispectral satellite images (e.g. SPOT, GeoEye, IKONOS, WorldView, Pleiades, etc.) and freely downloadable multispectral satellite images (e.g. USGS's LANDSAT-8 and ESA's Sentinel-2) in the market give us the continuously refreshed images of our Earth. Despite delivering the pretty picture for visualisation purpose, it also allows us to unlock the secrets and gain wealthy information out of the remotely sensed imagery.

The fundamental principle of extracting water depth information for bathymetric mapping using optical remote sensing data is the light, a range of visible wavelengths, can penetrate the water column in various degrees. The measured radiance is closely related to the incoming solar radiation, attenuation of radiation in and out of the atmosphere and water column, reflectance properties of the seabed (Figure 1). The depth of penetration is closely dependent on the environmental conditions such as biological growths, water quality, water turbidity, and water colour as well as water transparency (Gao, 2009). Generally, blue light is usually able to penetrate up to depths of thirty or possibly forty meters in clear water; and the red light is able to go through about five meters in clear water. While, NIR attenuates rapidly in water and does not penetrate further than one meters. The absorption and scattering of lights caused by the suspended sediment particles, dissolved organics and materials do affect the maximum depth of penetration in that particular water area.

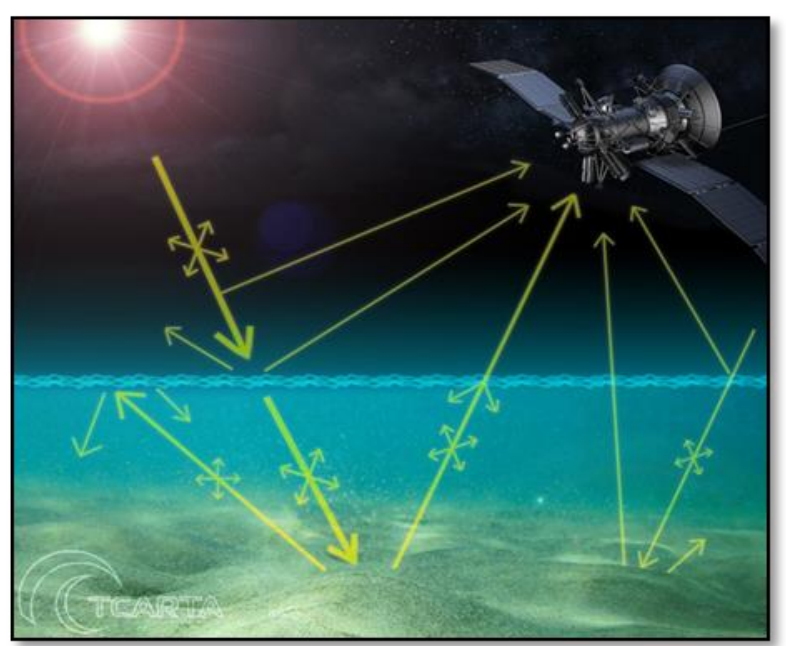

Figure 1. Satellite imagery-derived bathymetry (TCarta, 2018).

The method of extracting seabed information over clear shallow water using multispectral data and radiometric technique was first addressed by Lyzenga (1978). This radiometric technique is further developed by Lyzenga (1985) as well as being further explored by Benny and Dawson (1983), Spitzer and Driks 
(1987), Jupp (1988), Philpot (1989), Bierwirth (1993), Maritorena et al. (1994), Dierssen et al. (2003), Stumpf et al. (2003) and updated by Lyzenga et al. (2006). Throughout their remarkable hard works, a number of analytical, semi-analytical and empirical algorithms have been established to automatically extracting the water depth information for bathymetric mapping.

In previous studies, most of these bathymetry retrieval algorithms are reportedly practical in clear ocean waters (Jawak, Vadlamani, \& Luis, 2015; Jégat, Pe'eri, Freire, Klemm, \& Nyberg, 2016). This technique has proven itself as a useful reconnaissance tool of near-shore bathymetric mapping (Pe'eri et al., 2013; Jégat et al., 2016) and coastal monitoring in shallow water (Pacheco et al., 2014). According to Mavraeidopoulos et al. (2017), imagery-derived bathymetry has been utilized in nautical charting by some hydrographic offices as it is capable and accomplished to meet the total vertical uncertainty (TVU) specification as stated in the IHO's S-44 Classification of Surveys.

Nonetheless, this topic is relatively new and still less-explored in Malaysia (Najhan et al., 2017). Therefore, this present study takes the initiative to examine imagery-derived bathymetry approach to estimate the bathymetric depths along the highly turbid water in Malaysia. The main objective of this study is to evaluate the usability of space-borne imagery-derived bathymetric mapping technique in shallow and highly turbid waters in Strait of Johor.

\section{STUDY AREA}

Geographically, Malaysia is known as a maritime country with a total coastline length of 4,809 kilometres. The Malaysian coastline varies from scenic bays flanked by rocky headlands to shallow mud flats lined with mangrove forests (DID, 2017). On the east coast of Peninsular Malaysia (Figure 2), the high sediment yield from river discharges and harsher wave environment create the setting for a coastline of hook-shaped sandy bays facing the South China Sea. Meanwhile, on the west coast, the mild wave climate of the Strait of Malacca make for wide mud shores and coastal forests rich in biodiversity.

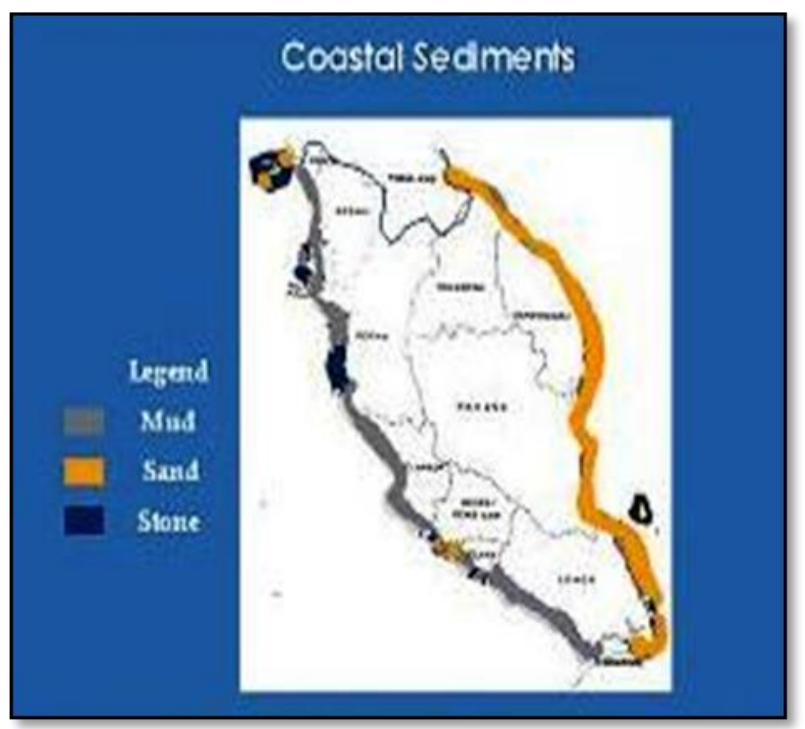

Figure 2. Coastal sediments along the coastline of Peninsular Malaysia (DID, 2017).

This present study makes an attempt to determine the bathymetric depths of the study area (Figure 3), focusing at the shallow and near shore coastal waters adjacent to Tanjung Kupang, Johor Bahru. It lies close to the equator between latitudes of $1^{\circ} 18^{\prime} 11^{\prime \prime} \mathrm{N}$ to $1^{\circ} 21^{\prime} 34^{\prime \prime} \mathrm{N}$ and longitudes of $103^{\circ} 33^{\prime} 58^{\prime \prime} \mathrm{E}$ to $103^{\circ} 37^{\prime} 52^{\prime \prime} \mathrm{E}$, situated in the middle of Strait of Johor which separates two neighbouring nations, Malaysia and Singapore.

Generally, this swampy area is vegetated by lavish mangroves and the shoreface is fronted by flat slopes with turbid suspended sediment. Besides the study area is one of the major container port, Pelabuhan Tanjung Pelepas in Malaysia. The water bordering this study area is vulnerable to human's pressure, currently undergoing huge land reclamation work. However the present study is examining its seabed topography before the iconic Forest City mega development project is being carrying out since middle of 2014.

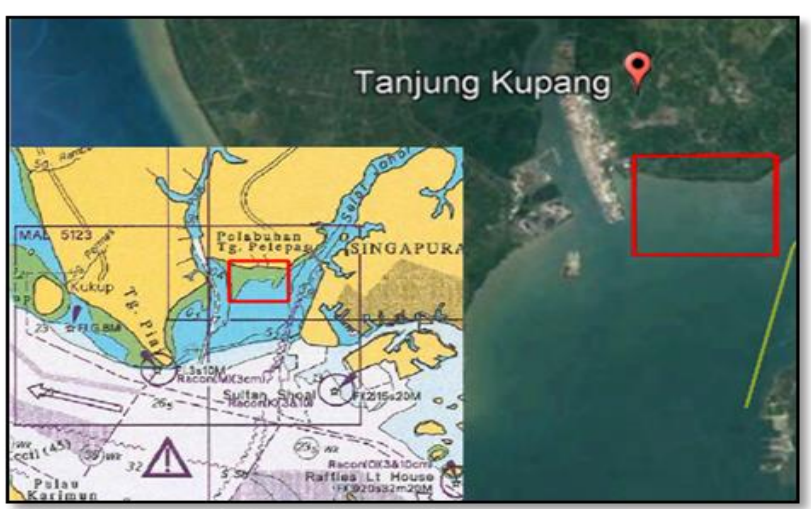

Figure 3. The study area of Tanjung Kupang at Strait of Johor.

In this area, the ability to routinely survey this area using acoustic vessel-based sounding methods (e.g. SBES, MBES, etc) has always been time consuming, costly and logistically challenging, particularly in relatively shallow and coastal water region. Rather than a single line measurement by SBES, MBES mounted onboard is capable of providing a full bottom coverage bathymetry. Nevertheless it may not be feasible to acquire bathymetric depth shallower than 2-3 metres water deep where survey swaths are narrow (Figure 4). Therefore, the state-of-theart imagery-derived bathymetry approach which does not have any mobilisation requirements for instance offers a fast, flexible, efficient and economically beneficial solution to map the seabed topography over this broad study area.

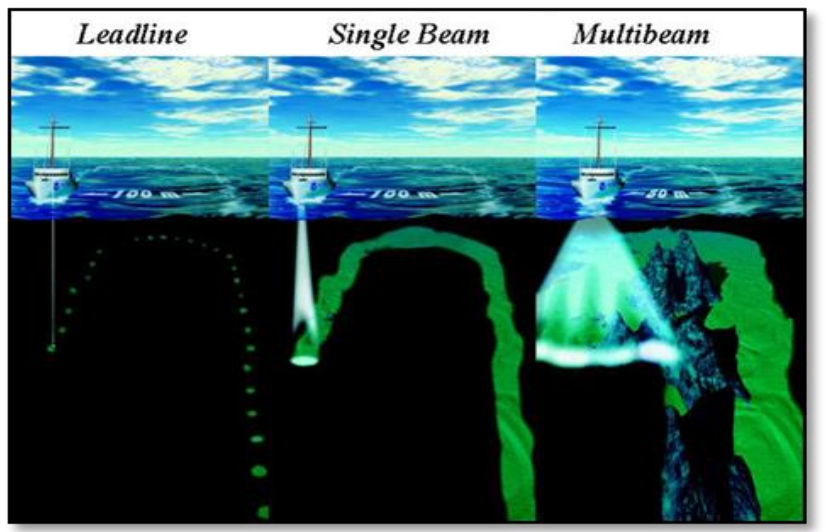

Figure 4. Bottom coverage by survey method (NOAA, 2018). 


\section{MATERIALS AND METHODS}

This section outlines the approaches being adopted here to derive coastal and shallow water bathymetric data from the remotely sensed satellite imagery. It is going to briefly review on the methods, bathymetry inversion models, technical specifications and characteristics of the multispectral images, ancillary datasets and digital image processing software being utilised in this study.

\subsection{Methodology}

This study incorporates space-borne remote sensing and GIS techniques to extract bathymetric depths from multispectral satellite images. It involves four major stages such as image pre-processing, measured water depth, model construction and accuracy assessment as shown in Figure 5 below.

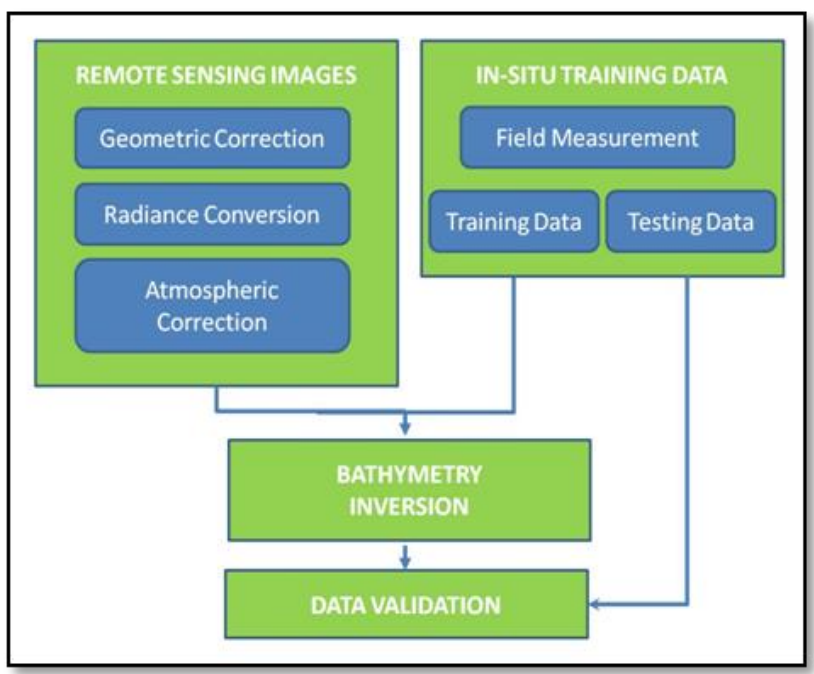

Figure 5. Flow chart of imagery-derived bathymetry.

Prior attempting to satellite image processing, pre-processing task such as radiometric, atmospheric and geometric correction have to be carried out in order to eliminate the atmospheric effects, unwanted path radiance, unnecessary sea surface reflectance as well as the distortion of the images. The tidallyreferenced in-situ bathymetric measurements are divided into two groups, basically the training data and testing data. Training data will be used to redevelop the most appropriate coefficient of correction in the depth-retrieval algorithm. At the end of the process, the newly constructed linear regression model is evaluated using the known measurements from the testing data.

\subsection{Multispectral Satellite Imagery}

Freely downloadable Landsat- 8 data flew pass the study area on 27th June 2013, at 12:50:59 hours (UTC Time) has been used to examine the proposed imagery-derived bathymetry approach. In order to optimize the processing task, these $30 \mathrm{bm}$ resolution multispectral images have been re-sampled into smaller area of which covers the entire study area located in Tanjung Kupang, Strait of Johor. Figure 6 shows the Landsat- 8 multispectral images used for this study.

Theoretically, short wavelengths are preferred in bathymetric mapping as these spectral bands have a greater penetration into aquatic environment. For instance, blue spectrum $(450-520 \mathrm{~nm})$ and green spectrum $(530-590 \mathrm{~nm})$ are selected for SDB mapping due to its low attenuation of electromagnetic radiation.
In this study, Band 2 (blue) and Band 3 (green) of the Landsat- 8 are chosen to fit into the SDB model.

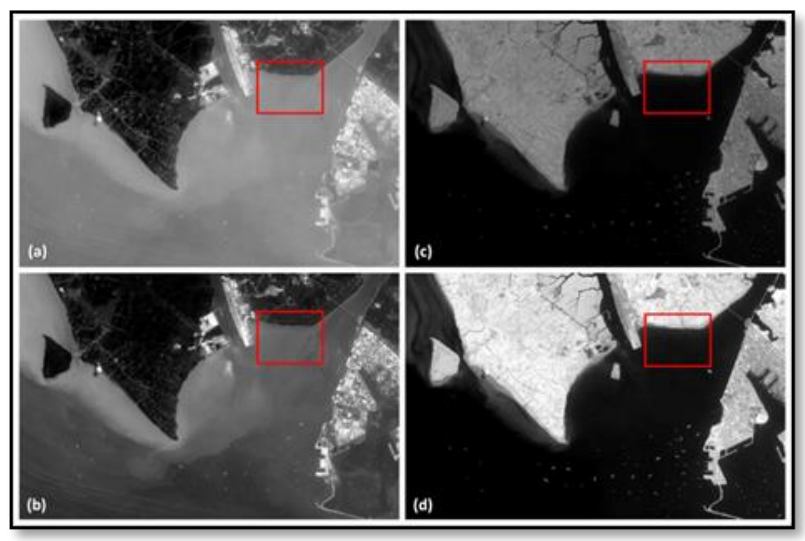

Figure 6. Landsat-8 multispectral satellite images of Tanjung

Kupang, Strait of Johor area. Image (a) Blue (Band 2); (b)

Green (Band 3); (c) Red (Band 4); and (d) NIR (Band 5).

\subsection{Nautical Chart}

The measured bathymetric depths are obtained from the nautical chart MAL 5123 - Port of Tanjung Pelepas (scale $1: 20,000$ ). Image to map registration has been performed to precisely georeference the particular multispectral images into the designated geographical coordinate system. The resultant orthorectified image allows for the accurate direct measurement of positions, distances and areas.

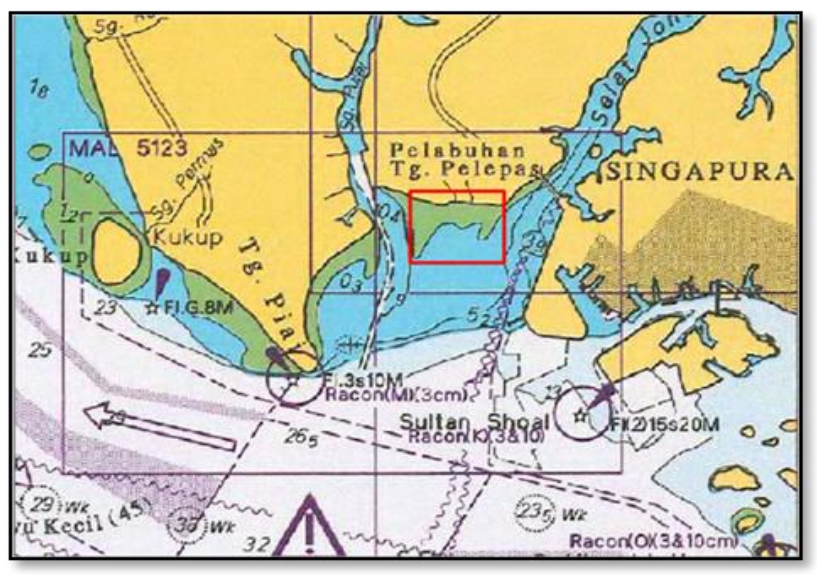

Figure 7. Nautical chart MAL5123.

\subsection{Field Survey for in-situ Bathymetry Observation}

The field survey was commenced on August 2013, using a small hydrographic boat fitted with Odom MK-III single beam echo sounder synchronized with precise position catered by Trimble DSM132 Differential-GNSS receiver to accurately measure the bathymetry depths. A total of more than 68,754 depth observations with 5 metres interval and 25 metres line spacing have been surveyed throughout the entire survey site (Figure 8).

To reduce the processing time, only partial of the survey depths will be utilised in this study. A total of 415 bathymetric points ranged from -0.597 metres to -6.992 metres have been chosen for the bathymetry inversion calibration process. They are measured from 6 survey lines within the designated survey site according to the well distributed survey planning lines. The in- 
situ bathymetric data is divided into two groups. Training data set is assigned for empirical modelling while a set of 189 samples depth testing data is designated for data verification and assessment. Since all the water depth measurements were tide affected, subsequently the absolute point observations were calculated after adjusted accordingly to the respective tidal correction with respect to mean sea level (MSL).

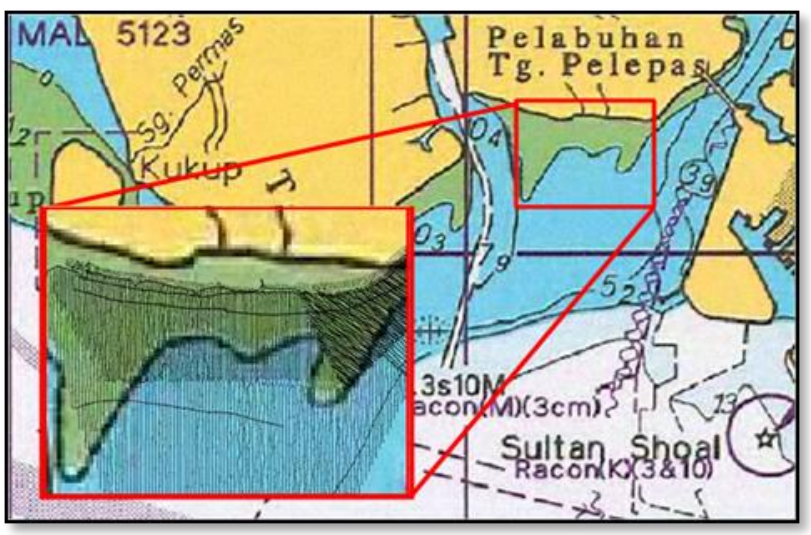

Figure 8 . The overview of the in-situ bathymetry survey data.

\section{BATHYMETRY INVERSION MODELS}

This study incorporated space-borne remote sensing and GIS techniques to extract bathymetric information or water depth from multispectral satellite images. It makes an attempt to determine the seabed topography over the shallow and turbid coastal region via two empirical approaches purposed by Stumpf et al. (2003) and Dierssen et al. (2003). Both models apply the fundamental principle of Beer-Lambert Law, intensity of light decreases exponentially with depth, to relate the observed reflectance from the optical sensor to the water depth. Theoretically, the linear inversion approach is able to empirically deriving the relationship between a pair of waterpenetrating wavelengths.

They use log-transform to linearize the relationship between ratio of reflectance in two respective bands and the desired water depth. The diffuse attenuation coefficient values of the two wavelengths will maintain a near-constant attenuation value throughout the water column. It is believed to be easier and suitable to be applied as well as is believed can determine the turbid coastal environment efficiently.

\subsection{Stumpf et al. Model}

Stumpf et al. (2003) has developed this simplified linear regression algorithm to determine the bathymetric depth $(\mathrm{Z})$ from two tuneable constant coefficients $\left(m_{0}\right.$ and $\left.m_{l}\right)$ and a ratio of observed reflectance of two consecutive bands $\left(R_{i}\right.$ and $\left.R_{j}\right)$. It uses the division between observed reflectance log values to estimated water depth. Equation 1 below demonstrates the Stumpf et al.'s algorithm:

$$
Z=\mathrm{m}_{0} * \frac{\ln \left(\mathrm{R}_{\mathrm{w}}\left(\lambda_{1}\right)\right)}{\ln \left(\mathrm{R}_{\mathrm{w}}\left(\lambda_{1}\right)\right)}-\mathrm{m}_{1}
$$

where $Z=$ depth value from derived depth

$R_{w}=$ observed reflectance value of band $i$ and band $j$

$m_{0}=$ tuneable constant to scale the ratio to depth

$m_{l}=$ offset of a depth

$n=$ constant value

\subsection{Dierssen et al. Model}

Dierssen et al. (2003) has also developed a similar band-ratio concept to estimate the bathymetric depth (Z). It is presented slightly different by model the difference between observed reflectance $\log$ values. The estimated water depth is mathematically calculated from two tuneable constant coefficients $\left(m_{0}\right.$ and $\left.m_{l}\right)$ and a log-difference between the observed reflectance of two consecutive bands $\left(R_{\mathrm{i}}\right.$ and $\left.R_{j}\right)$. Equation 2 below demonstrates the Dierssen et al.'s algorithm:

$$
Z=m_{0} * \ln \left[\frac{n R_{w}\left(\lambda_{1}\right)}{n R_{w}\left(\lambda_{1}\right)}\right]+m_{1}
$$

where

$$
\begin{aligned}
& Z=\text { depth value from derived depth } \\
& R_{w}=\text { observed reflectance value of band } i \text { and band } j \\
& m_{0}=\text { tuneable constant to scale the ratio to depth } \\
& m_{l}=\text { offset of a depth } \\
& n=\text { constant value }
\end{aligned}
$$

\section{RESULTS AND DISCUSSIONS}

\subsection{Imagery-Derived Bathymetry Models}

Two simple linear regression analysis is performed on the 415 training points and the final bathymetry models are produced. In general both imagery-derived bathymetry algorithms have successfully produced fairly accurate results. Figure 9 and Figure 10 below show the overview depth estimation models formed via Stumpf et al.'s and Dierssen et al.'s band ratio approach respectively.

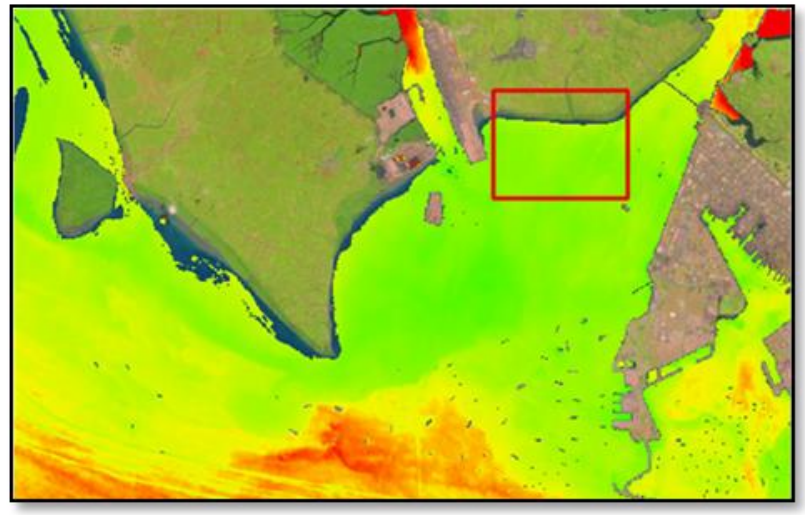

Figure 9. Overview imagery-derived bathymetric model from Stumpf et al's band ratio approach.

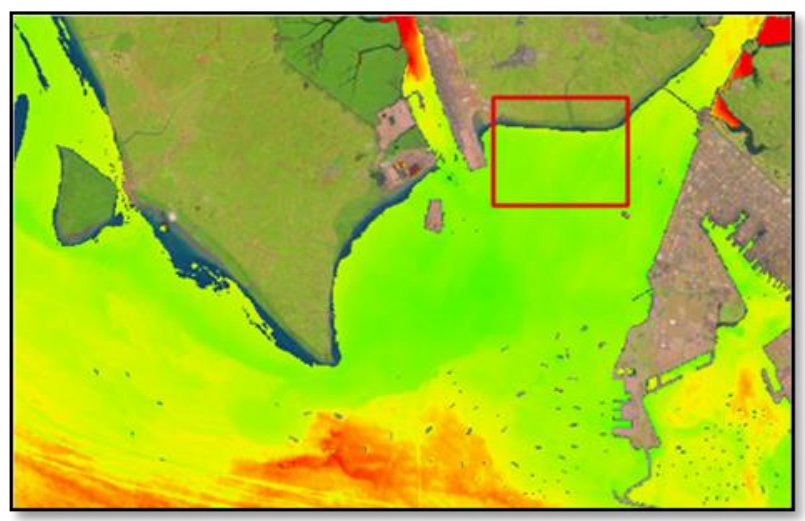

Figure 10. Overview imagery-derived bathymetric model from Dierssen et al's band ratio approach. 
Figure 11 and Figure 12 below illustrate the bathymetric models specifically focusing on the study area in this study. They are extracted out from the models above so that a more specific analysis can be conducted on the near shore area.

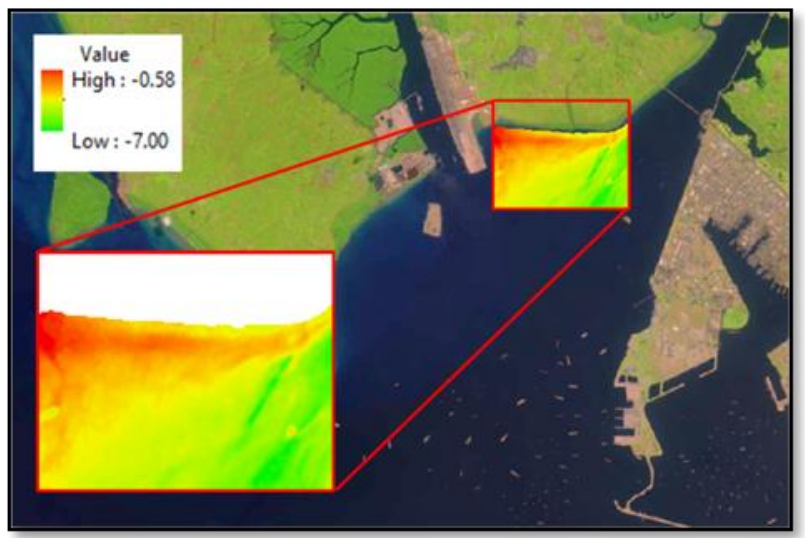

Figure 11. Imagery-derived bathymetric model (study area) from Stumpf et al's band ratio approach.

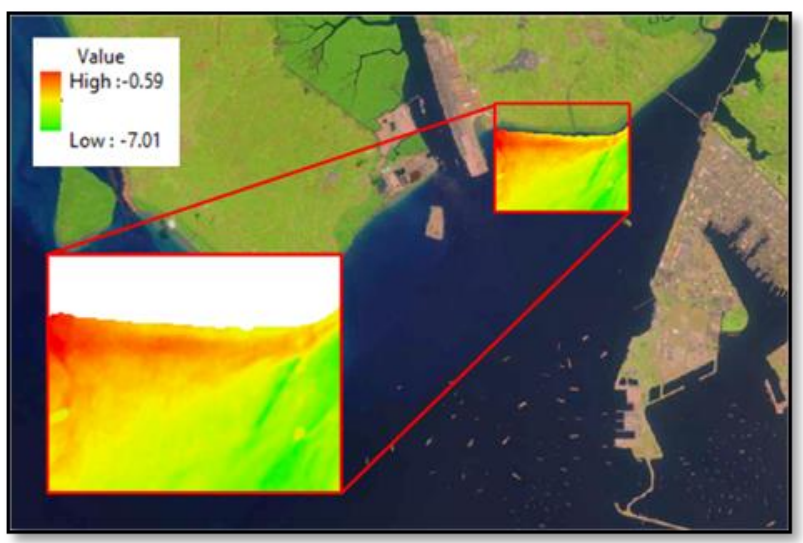

Figure 12. Imagery-derived bathymetric model (study area) from Dierssen et al's band ratio approach.

\subsection{Validation}

The data assessment or commonly known as the quality assurance, is an important step in the determining the usability of the estimated data. Indeed, it is primarily an evaluation of performance against the known depth, either from in-situ vessel-based bathymetric survey data or endorsed data extracted from the nautical charts.

The assessment of accuracy is made by comparing the imageryderived bathymetry with the 200 random bathymetric data (Figure 13) acquired using SBES. The accuracy of each model is assessed using simple statistical models such as root mean square error (RMSE), mean absolute error (MAE) and correlation coefficient (r). The quantitative analysis RMSE equations, MAE equation and $r$ are shown in Equation 3, 4 and 5 below.

$$
\begin{aligned}
\text { RMSE } & =\sqrt{\frac{\sum_{\mathrm{i}=1}^{\mathrm{n}}\left(\mathrm{x}_{\mathrm{i}}-\mathrm{y}_{\mathrm{i}}\right)}{\mathrm{n}}} \\
\text { MAE } & =\frac{\sum_{\mathrm{i}=1}^{\mathrm{n}} \mathrm{abs}\left(\mathrm{x}_{\mathrm{i}}-\mathrm{y}_{\mathrm{i}}\right)}{\mathrm{n}}
\end{aligned}
$$

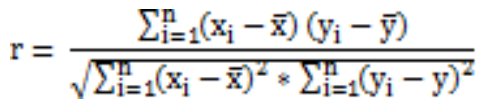

where $\quad x_{i}=$ value derived depth

$y_{i}=$ depth value from field measurement

$\ddot{x}=$ mean value from derived depth

$\bar{y}=$ offset of a depth

$n=$ number of observation

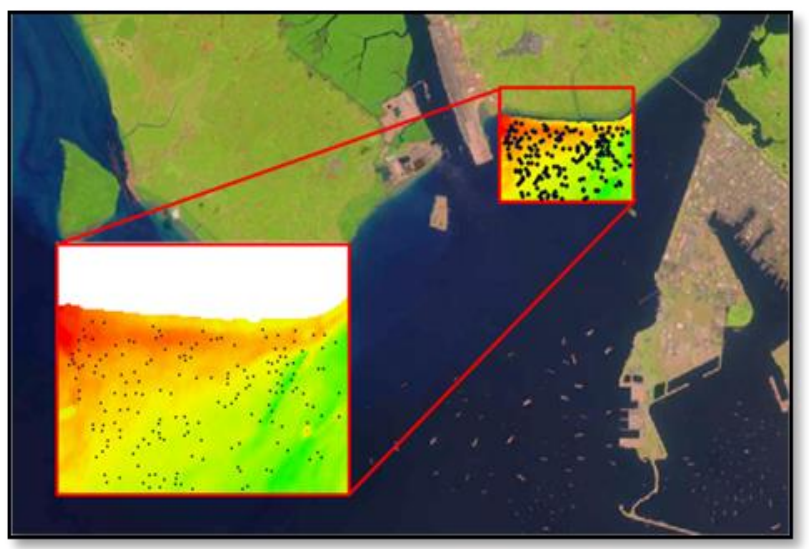

Figure 13. Random bathymetric data acquire using SBES.

The overall results for both derivation models are described in Table 1 below. The statistical analysis shows that Dierssen et al.'s model obtains RMSE of 0.878 metres while Staumpf et al's model delivers RMSE of 0.885 metres. While, the absolute differences between known depths and estimated depths at those points vary from 0.005 metres to 3.245 metres with the MAE equals to 0.629 metres for Dierssen et al.'s model, whilst the MAE obtains by Stumpf et al.'s model is 0.631 metres. In the meantime, to validate the models, the correlation coefficient (r) is computed. Both models show a similar correlation coefficient of 0.76. Generally, the outcomes of the statistical analysis indicate that the imagery-derived bathymetry models provide satisfied results in this highly turbid water region.

\begin{tabular}{|c|c|c|c|}
\hline \multirow{2}{*}{$\begin{array}{c}\text { Band Ratio } \\
\text { Model }\end{array}$} & $\begin{array}{c}|c| \\
\text { Square Error } \\
\text { (RMSE) }\end{array}$ & $\begin{array}{c}\text { Mean Absolute } \\
\text { Error (MAE) }\end{array}$ & $\begin{array}{c}\text { Correlation } \\
\text { Coefficient } \\
\text { (r) }\end{array}$ \\
\hline $\begin{array}{c}\text { Stumpf et al. } \\
\text { Model }\end{array}$ & 0.885 & 0.631 & 0.76 \\
\hline $\begin{array}{c}\text { Dierssen et. } \\
\text { al. Model }\end{array}$ & 0.878 & 0.629 & 0.76 \\
\hline
\end{tabular}

Table 1. Statistical results based on the Stumpf et al.'s model and Dierssen et al.'s model.

Apart from the abovementioned statistical results, imageryderived bathymetry depths for each model are plotted against the SBES. Figure 14 below shows the depth profile along 4 transects (orientated southwards) over the designated study area. The SBES depths and another two modelled depths produced by Stumpf et al.'s model and Dierssen et al.'s model along the 4 cross-shore profile plots are illustrated in Figure 15 below. 


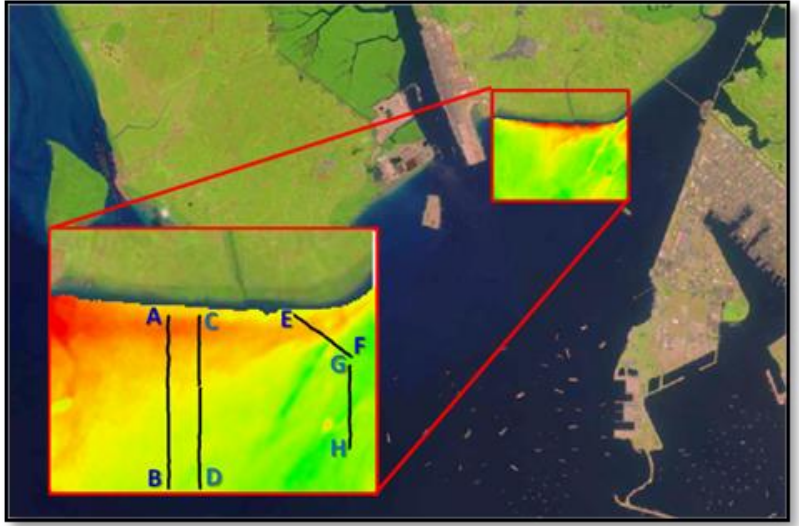

Figure 14. Location of the 4 different cross-shore profiles (chainage A-B, C-D, E-F \& G-H) for depth validations.

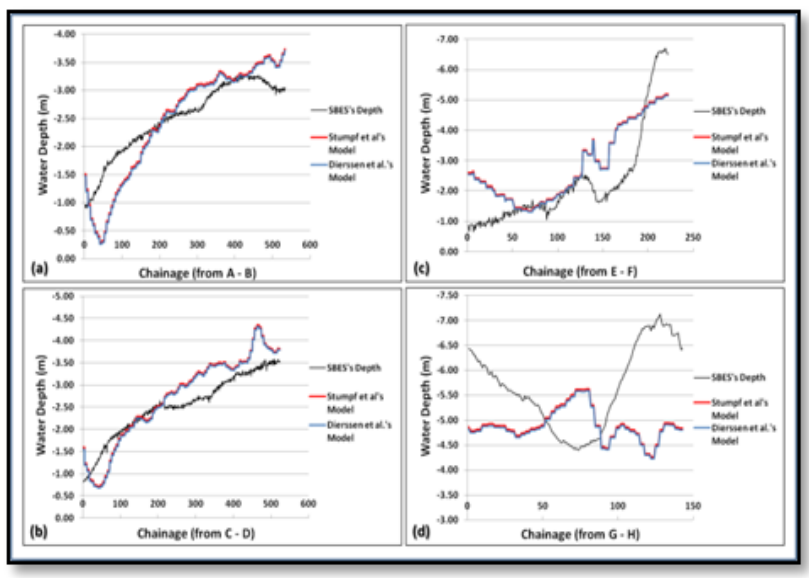

Figure 15. Cross-shore profiles of SBES and modelled depths spaced at the designated chainage. Validation plot (a) chainage A-B; (b) chainage C-D; chainage E-F; and (d) chainage G-H.

Based on the validation plots above, it is clear that the Stumpf et al.'s model and Dierssen et al.'s performed similarly throughout the 4 cross-shore profiles. From Figure 15 (a), (b) and (c), it seems likely that these two empirical models do not perform accordingly are at the very shallow water with the depth less than 1.5 metres. Meanwhile, it is quite reliable and does not show great uncertainty at the water depths ranged from 1.5 metres to 4.5 metres over those 3 different regions. By contrast, it can be clearly observed that both modelled depths have huge uncertainty at the water depth greater than 4.5 metres from Figure 15 (c) and (d).

\subsection{Discussion}

In the course of experiment, there are no overwhelming differences between the results from Stumpf et al.'s model and Dierssen et al.'s model. A key assumption in this study is that the water column contribution and the bottom returns for the pair of wavelengths are approximately constant over the entire scene. Although these two algorithms are slightly different, but the end results produced are quite close in this study.

In imagery-derived bathymetry, water clarity or turbidity is always determined as a key factor that determines the penetration of light in water. It will lead to a false shoaling in the empirical models for depth retrieval from multispectral images. The shallow water regions with the depths below 1.5 metres and greater than 4.5 metres have demonstrated huge uncertainty due to its false reflected radiance values. A possible explanation to the failure to control those areas is that the dark submerged mud has affected the linear relationship between water reflectance and depth. This turbid environmental condition poses a challenge in imagery-derived bathymetry. Hence, it seems that a single linear band ratio regression approach may not work perfectly in turbid and muddy regions.

Like most scientific investigations, the results indicate the need for further research on separating the testing area into several depth zones and use more ground-truthing samples to determine the suitable linear regression analysis on each defined zone. Such approach will form multiple linear regression models and perfectly determine the constant diffuse attenuation coefficients on each designated depth zone.

\section{CONCLUSIONS}

This study examines usability of satellite imagery-derived bathymetry in shallow and highly turbid waters in Strait of Johor, Malaysia. Throughout this experiment, a comparative analysis of two band ratio empirical models using training data obtained via SBES has been made. The Stumpf et al.'s model makes use of a linear regression of depth to band ratio and has achieved a RMSE of 0.885 metres while Dierssen et al.'s model delivers the RMSE value of 0.878 metres. Overall, both models also show a reasonable agreement, with similar correlation coefficient value of 0.76 . The results presented above show that both empirical models represent a promising outcome and can be used to complement data from SBES, which normally obtained at medium (interval $<10$ metres) to course (interval $>20$ metres) profiling resolution for the purpose of survey reconnaissance and survey planning. Also, by stacking a timeseries with historical data, it is possible to distinguish the seabed topography and coastline changes.

\section{ACKNOWLEDGEMENTS}

The authors would like to thank the Department of Survey and Mapping Malaysia, National Hydrographic Centre, GeoCoastal Research Unit (Geospatial Imaging and Information Research Group) and Research Management Centre, Universiti Teknologi Malaysia. This research would not have been possible without their technical supports and financial aids under Research University Grant (Vote Number: Q.J130000.2527.17H97).

\section{REFERENCES}

Baillarin, S., Meygret, A., Dechoz, C., Petrucci, B., Lacherade, S., Tremas, T., Spoto, F. (2012). Sentinel-2 level 1 products and image processing performances. Paper presented at the Geoscience and Remote Sensing Symposium (IGARSS), 2012 IEEE International.

Bramante, J. F., Raju, D. K., \& Sin, T. M. (2013). Multispectral derivation of bathymetry in Singapore's shallow, turbid waters. International journal of remote sensing, 34(6), 20702088.

Benny, A., \& Dawson, G. (1983). Satellite imagery as an aid to bathymetric charting in the Red Sea. The Cartographic Journal, 20(1), 5-16.

Bierwirth, P., Lee, T., \& Burne, R. (1993). Shallow sea-floor reflectance and water depth derived by unmixing multispectral 
images. Photogrammetric Engineering and Remote Sensing;(United States), 59(3).

Dierssen, H. M., Zimmerman, R. C., Leathers, R. A., Downes, T. V., \& Davis, C. O. (2003). Ocean color remote sensing of seagrass and bathymetry in the Bahamas Banks by high- resolution airborne imagery. Limnology and Oceanography, 48(1part2), 444-455.

Doxani, G., Papadopoulou, M., Lafazani, P., Pikridas, C., \& Tsakiri-Strati, M. (2012). Shallow-water bathymetry over variable bottom types using multispectral Worldview-2 image. International Archives of the Photogrammetry, Remote Sensing and Spatial Information Sciences, 39(8), 159-164.

Gao, J. (2009). Bathymetric mapping by means of remote sensing: methods, accuracy and limitations. Progress in Physical Geography, 33(1), 103-116.

Hamylton, S. M., Hedley, J. D., \& Beaman, R. J. (2015). Derivation of high-resolution bathymetry from multispectral satellite imagery: a comparison of empirical and optimisation methods through geographical error analysis. Remote Sensing, 7(12), 16257-16273. doi:10.3390/rs71215829

Jawak, S. D., Vadlamani, S. S., \& Luis, A. J. (2015). A synoptic review on deriving bathymetry information using remote sensing technologies: models, methods and comparisons. Advances in Remote Sensing, 4(02), 147.

Ji, L., Zhang, L., \& Wylie, B. (2009). Analysis of dynamic thresholds for the normalized difference water index. Photogrammetric Engineering \& Remote Sensing, 75(11), 1307-1317.

Jupp, D. (1988). Background and extensions to depth of penetration (DOP) mapping in shallow coastal waters. Paper presented at the Symposium on Remote Sensing of the Coastal Zone, Gold Coast, Queensland.

Lyzenga, D. R. (1978). Passive remote sensing techniques for mapping water depth and bottom features. Appl Opt, 17(3), 379383. doi:10.1364/AO.17.000379

Lyzenga, D. R. (1985). Shallow-water bathymetry using combined lidar and passive multispectral scanner data. International journal of remote sensing, 6(1), 115-125.

Lyzenga, D. R., Malinas, N. R., \& Tanis, F. J. (2006). Multispectral bathymetry using a simple physically based algorithm. Ieee Transactions on Geoscience and Remote Sensing, 44(8), 2251-2259. doi:10.1109/Tgrs.2006.872909

Mobley, C. D. (1994). Light and water: radiative transfer in natural waters: Academic press.

Pacheco, A., Horta, J., Loureiro, C., \& Ferreira, Ó. (2015). Retrieval of nearshore bathymetry from Landsat 8 images: a tool for coastal monitoring in shallow waters. Remote sensing of environment, 159, 102-116.

Pe'eri, S., Madore, B., Nyberg, J., Snyder, L., Parrish, C., \& Smith, S. (2016). Identifying bathymetric differences over alaska's north slope using a satellite-derived bathymetry multitemporal approach. Journal of Coastal Research, 56-63. doi:10.2112/Si76-006
Pe'eri, S., Parrish, C., Azuike, C., Alexander, L., \& Armstrong, A. (2014). Satellite remote sensing as a reconnaissance tool for assessing nautical chart adequacy and completeness. Marine Geodesy, 37(3), 293-314. doi:10.1080/01490419.2014.902880

Philpot, W., Davis, C. O., Bissett, W. P., Mobley, C. D., Kohler, D. D., Lee, Z.,Trowbridge, J. (2004). Bottom characterization from hyperspectral image data. Oceanography, 17(2), 76-85.

Philpot, W. D. (1989). Bathymetric mapping with passive multispectral imagery. Applied optics, 28(8), 1569-1578.

Sam, L., Prusty, G., \& Gahlot, N. (2017). Evaluation of optical remote sensing-based shallow water bathymetry for recursive mapping. Geocarto International, 1-17.

Said, N. M., Mahmud, M. R., \& Hasan, R. C. (2017). Satellitederived bathymetry: Accuracy assessment on depths derivation algorithm for shallow water area. International Archives of the Photogrammetry, Remote Sensing \& Spatial Information Sciences, 42.

Said, N. M., Mahmud, M. R., \& Hasan, R. C. (2017). Satellitederived bathymetry: Optimising new promising technology for low-water line (baselines) delineation. Paper presented at the $9^{\text {th }}$ ABLOS Conference 2017, Monaco.

Sánchez-Carnero, N., Ojeda-Zujar, J., Rodríguez-Pérez, D., \& Marquez-Perez, J. (2014). Assessment of different models for bathymetry calculation using SPOT multispectral images in a high-turbidity area: the mouth of the Guadiana Estuary. International journal of remote sensing, 35(2), 493-514.

Spitzer, D., \& Dirks, R. (1986). Classification of bottom composition and bathymetry of shallow waters by passive remote sensing. Paper presented at the IN: Remote sensing for resources development and environmental management; Proceedings of the Seventh International Symposium, Enschede, Netherlands, Aug. 25-29, 1986. Volume 2 (A8841961 17-43). Rotterdam, AA Balkema, 1986, p. 775-777.

Stumpf, R. P., Holderied, K., \& Sinclair, M. (2003). Determination of water depth with high-resolution satellite imagery over variable bottom types. Limnology and Oceanography, 48(1), 547-556.

Su, H. B., Liu, H. X., \& Heyman, W. D. (2008). Automated derivation of bathymetric information from multi-spectral satellite imagery using a non-linear inversion model. Marine Geodesy, 31(4), 281-298. doi:Pii 906372417

$10.1080 / 01490410802466652$

Tang, K.K.W., \& Pradhan, B. (2015). Converting digital number into bathymetric depth: A case study over coastal and shallow water of Langkawi Island, Malaysia. Paper presented at the FIG Working Week 2015, Sofia, Balgeria.

Zheng, G., Chen, F., \& Shen, Y. (2017). Detecting the water depth of the South China Sea reef area from WorldView-2 satellite imagery. Earth Science Informatics, 10(3), 331-337.

Revised August 2018 